oldest and probably one of the most effective methods for controlling infectious disease outbreaks. However, governments of many countries have difficulty implementing social distancing, particularly in developing countries such as Brazil, where income inequality is high and the national economy is fragile.

Several studies in the literature, both in developed and developing countries, have demonstrated the effectiveness of social distancing in slowing the spread of COVID-19., In a recent study, Taghrir et $\mathrm{al}^{1}$ investigated the efficacy of mass quarantine during the pandemic and found good-quality evidence for the social distancing strategies to have been highly effective in controlling the spread of the disease. Complementing this analysis, other researchers analyzed data of 8 countries extremely affected by COVID-19: China, Italy, Iran, Germany, France, Spain, South Korea, and Japan. They concluded that the rapidly increasing COVID-19 case numbers in European countries occurs due to late contention measures ${ }^{2}$. Therefore, social distancing is currently the most effective way to slow the spread of COVID-19.

In Brazil, the Ministry of Health recommended measures of social distancing, respiratory etiquette, and hand hygiene. ${ }^{3}$ Social distancing measures included the closing of schools, universities, and almost all shops, except food stores and pharmacies. In addition, cafes, restaurants, clubs, gyms, museums, and other institutions across the country have closed. Public gatherings, religious services, and social and sporting events have been cancelled. Nonetheless, the number of cases for COVID-19 has continued to grow exponentially due to difficulties in establishing true and effective social distancing. In the real Brazilian context, a large number of informal workers are still working normally and there is a lack of access to information for a large part of the population regarding minimum infection prevention and control measures, including hand washing and respiratory etiquette.

Although handwashing and social distancing are still the best measures to protect against the virus, the flattening the COVID19 curve will require additional measures in developing countries, where the spreading factor of the virus are different and more complex. In Brazil, it is essential to better understand the true prevalence of COVID-19, but the lack of mass testing is one of the main problems that make it difficult to implement measures to ensure that infected individuals are in an appropriate quarantine. Here, the physical distancing between infected and people is crucial in the high-risk group, such as the elderly and those with respiratory or chronic illnesses, to reduce the lethal effect of the pandemic.

According to the $\mathrm{WHO}$, wearing a surgical mask, in combination with hand hygiene and other preventative measures, is one of the prevention measures to limit the spread of SARS-CoV-2 in affected areas. ${ }^{4}$ Cowling et $\mathrm{al}^{5}$ demonstrated that the implementation of social distancing measures and changes in population behaviors, including use of facial masks, were associated with reduced transmission of SARS-CoV-2 in Hong Kong. In Brazil, the adoption of this equipment can be difficult due to the low adhesion or the lack of access to facial masks by the Brazilian population. Thus, the correct use of facial masks is fundamental to the effectiveness of the measure and can be encouraged and improved through education campaigns.

In Brazil, coronavirus is advancing exponentially. Although the disease has spread rapidly in large capitals, where the incidence of cases is high, COVID-19 cases are increasing in smaller cities and poorer communities as well. More than three-quarters of the confirmed cases are in southern and southeastern regions of Brazil, which are more densely populated, including many elderly, and with tropical and subtropical climates. In addition, the economic burden that sustained distancing can impose is potentially catastrophic in Brazil and other developing countries. Furthermore, if social distancing is not effective and/or is not sustained for long enough, the healthcare system may collapse, contributing to a greater tragedy.

Acknowledgments. The authors would like to thank the Brazilian research and development agencies for supporting this article.

Financial support. This work was supported by Coordenação de Aperfeiçoamento de Pessoal de Nível Superior (CAPES), by Brazilian National Council for Scientific and Technological Development (CNPq), and by Fundação de Amparo à Pesquisa do Estado de Minas Gerais (FAPEMIG). This letter was based on observations and reflections about the COVID-19 pandemic during studies supported by the funding agencies.

Conflicts of interest. All authors report no conflicts of interest related to this work.

\section{References}

1. Taghrir MH, Akbarialiabad H, Ahmadi Marzaleh M. Efficacy of mass quarantine as leverage of health system governance during COVID-19 outbreak: a mini policy review. Arch Iran Med 2020;23:265-267.

2. Parmet WE, Sinha MS. The law and limits of quarantine. $N$ Engl J Med 2020;382(15):e28.

3. Medidas Não Farmacológicas [in Italian]. Ministério da Saúde website. https://coronavirus.saude.gov.br/. Published 2020. Accessed April 27, 2020.

4. Advice on the use of masks the community, during homecare and in healthcare settings in the context of the novel coronavirus (2019-nCoV). Outbreak Interim Guidance. World Health Organization website. https://www.who. int/publications-detail/ Published 2020. Accessed April 27, 2020.

5. Cowling BJ, Ali ST, Ng TWY, et al. Impact assessment of non-pharmaceutical interventions against coronavirus disease 2019 and influenza in Hong Kong: an observational study. Lancet Public Health 2020; pii: S2468-2667(20)30090-6.

\title{
Double masking: Does science coincide with common sense?
}

\author{
Jeffrey T. Mueller $\mathrm{MD}^{1}$ (1), Soroor Karimi $\mathrm{PhD}^{2}$, Karl A. Poterack $\mathrm{MD}^{1}$, Maria Teresa A. Seville $\mathrm{MD}^{3}$ and \\ Steven M. Tipton $\mathrm{PhD}^{2}$ \\ ${ }^{1}$ Department of Anesthesiology, Mayo Clinic College of Medicine and Science, Phoenix, Arizona, ${ }^{2}$ Department of Mechanical Engineering, University of Tulsa, \\ Tulsa, Oklahoma and ${ }^{3}$ Division of Infectious Diseases, Mayo Clinic College of Medicine and Science, Phoenix, Arizona
}

Author for correspondence: Jeffrey T. Mueller, E-mail: mueller.jeff@mayo.edu

Cite this article: Mueller JT, et al. (2022). Double masking: Does science coincide with common sense?. Infection Control \& Hospital Epidemiology, 43: 954-955, https://doi.org/ 10.1017/ice.2021.155
To the Editor-The importance of nonpharmaceutical interventions in preventing the spread of severe acute respiratory syndrome 
coronavirus 2 (SARS-CoV-2) is clearly established, and their ongoing improvement must include all available expertise within science, medicine, and engineering. The nonpharmaceutical intervention of masking, specifically the potential incremental benefit of wearing 2 or more masks, is currently receiving considerable attention. ${ }^{1}$ When asked about the possible benefit of wearing 2 masks during a January 25, 2021, Today Show interview, Dr Anthony Fauci responded, "So, if you have a physical covering with one layer, you put another layer on, it just makes common sense that it likely would be more effective." Subsequent news stories have provided further perspectives on this concept; most create a sense of probable benefit and no potential harm. ${ }^{2}$ In addition, a recent limited study suggested the benefit of improving mask fit and decreasing leakage by wearing a cloth mask over a poorly fitting surgical mask based upon controlled bench tests. ${ }^{3}$ More fully understanding the potential risks and benefits of double masking is very relevant for both the general public and for providers practicing in current and future clinical environments subject to personal protective equipment scarcity.

Although the overall benefit of simple public masking is well accepted, the degree of individual benefit is determined by several variables including mask materials, design, cleanliness, fit, and the technique used for placement and removal. All cloth, surgical, and medical masks (referred to as surgical masks in this letter) are filters through which some, but not all, of a user's respiratory airflow passes. Grinshpun et $\mathrm{al}^{4}$ demonstrated that 5-6 times more contaminants reach users through leakage around surgical masks versus those which pass through the mask's filter media. Drewnick et $\mathrm{al}^{5}$ have reported additional results emphasizing the importance of leakage. The ratio of airflow leaking around versus passing through the mask is determined in part by the mask's resistance to airflow and the related pressure difference across the mask: the higher the resistance and associated pressure difference for a given inhalational airflow, the greater the amount of air that will leak or be shunted around the mask and into the airway. The same problem could occur during exhalation and thus impair the mask's protection of others. We recently presented a mathematical analysis of a similar potential problem when surgical masks are worn over N95 filtering facepiece respirators. ${ }^{6}$ Unlike N95 filtering facepiece respirators, surgical masks have no intended true seal between the mask edge and the face, making shunting or leakage around the mask edges an expected design characteristic.

The incremental benefit of the increased filtration efficiency created by using multiple masks could be negated or even exceeded by the incremental harm of increased leakage around the masks. That is, additional masks might provide better filtration of a reduced fraction and cause an increase in the unfiltered fraction of total airflow (Fig. 1). Accurately determining the net protective effect of beneficial versus harmful factors in a 2-mask scenario is a significant engineering and fluid mechanics problem. Attempts to understand SARS-CoV-2 transmission problems such as this one must recognize the complex and nonintuitive nature of aerosol

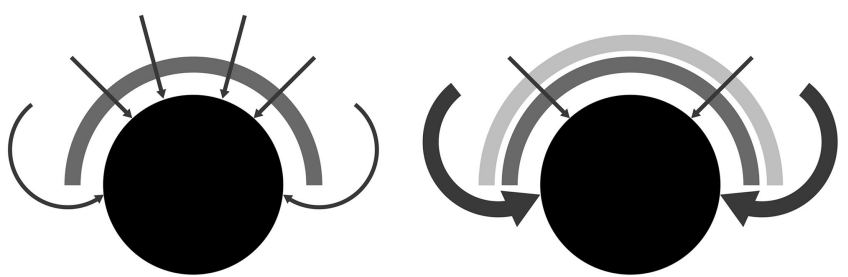

Fig. 1. Schematic diagram of single and double masking, displaying the possible scenario of increased respiratory airflow leakage due to increased mask resistance.

and airflow physics. ${ }^{7}$ The net effect could vary with individual mask designs, minute ventilation, airway pressures, facial anatomy, and facial movement. It is also important that empirical and analytical models recognize the cyclical, time-variable nature of respiratory airflow, and that peak impulses of pressure and flow will create the intervals of maximum leakage. These variables and possibly others will determine the concerning fraction of respiratory airflow that passes between the edges of a surgical mask and the face. Additional experimental and analytical investigations are necessary to produce an evidence-based assessment of the risks and benefits of double masking.

Acknowledgment.

Financial support. No financial support was provided relevant to this article.

Conflicts of interest. All authors report no conflicts of interest relevant to this article.

\section{References}

1. Wu KJ. One mask is good. Would two be better? New York Times website. https://www.nytimes.com/2021/01/12/health/coronavirus-masks-transmission. html. Published 2021. Accessed February 24, 2021.

2. Godoy M. Five hacks and tips to make your face mask more protective. Shots: health news from NPR. National Public Radio website. https://www.npr.org/ sections/health-shots/2021/02/03/962197192/5-hacks-to-make-your-face-maskmore-protective. Published 2021. Accessed February 24, 2021.

3. Brooks JT, Beezhold DH, Noti JD, et al. Maximizing fit for cloth and medical procedure masks to improve performance and reduce SARS-CoV-2 transmission and exposure, 2021. Morb Mortal Wkly Rep 2021;70:254-257.

4. Grinshpun SA, Haruta H, Eninger RM, Reponen T, McKay RT, Lee SA. Performance of an N95 filtering facepiece particulate respirator and a surgical mask during human breathing: two pathways for particle penetration. J Occup Environ Hyg 2009;6:593-603.

5. Drewnick F, Pikmann J, Fachinger F, Moormann L, Sprang F, Borrmann S. Aerosol filtration efficiency of household materials for homemade face masks: Influence of material properties, particle size, particle electrical charge, face velocity, and leaks. Aerosol Sci Tech 2021;55:63-79.

6. Mueller JT, Karimi S, Poterack KA, Seville MTA, Tipton SM. Surgical mask covering of N95 filtering facepiece respirators: the risk of increased leakage. Infect Control Hosp Epidemiol 2021. doi: 10.1017/ice.2021.50.

7. Mittal R, Ni R, Seo JH. The flow physics of COVID-19. J Fluid Mech 2020;894: F2 1-11. 